\title{
Antioxidant, anti-microbial and anti-cancer effectiveness of marine macro alga Ulva fasciata Delile.
}

\author{
Langeswaran $\mathrm{K}^{1^{*}}$, Santhosh Kumar $\mathbf{S}^{2}$, Gavaskar $\mathrm{S}^{3}$ \\ ${ }^{1}$ Cancer Genetics and Molecular Biology Laboratory, Department of Bioinformatics, Alagappa University, Karaikudi, \\ Tamil Nadu, India \\ ${ }^{2}$ Department of Computer Science, Alagappa University, Karaikudi, Tamil Nadu, India \\ ${ }^{3}$ Department of Computer Application, Bharathiyar University, Tamil Nadu, India
}

\begin{abstract}
Backround: Cancer is a sever burden and a fatal disease in the existing century and worldwide measured as a foremost health concern.

Objective: The present analysis involved in evaluating the anti-tumour property of Ulva fasciata Delile in in vitro model and anti-microbial activity against pathogens.

Materials and methods: The anti-cancer effectiveness of methanolic extract of Ulva fasciata has been identified at different concentrations after 24 hours of exposure of HepG2 cells using assays.

Results: The seaweed extract showed a remarkable cell toxicity potential at the concentration of 100 $\mu \mathrm{g} / \mathrm{ml}$ with superfluous ROS formation and lactate dehydrogenase and GSH enzyme release and initiating severe damage to the mitochondrial integrity of the cells.

Conclusion: This investigation displayed that the methanolic extract of UIva fasciata were more potential seaweed triggering cytotoxicity, inducing apoptosis and establishment of ROS dependent mitochondrial damage induced cytotoxicity in $\mathrm{HepG2}$ cells. The sea weed extract exhibits significant anti-microbial activity against pathogenic bacteria and fungi and anti-cancer efficacy.
\end{abstract}

Keywords: Marine alga, Ulva fasciata, Sea weeds, Hepatocellular carcinoma, Anti-microbial activity.

Accepted on June 11, 2019

\section{Introduction}

Hepatocellular carcinoma (HCC) is the third prime primary liver malignancy with high epidemiological prevalence and mortality rate. HCC rate of incidence is higher in developing countries and it is gradually increasing in developed nations yearly [1]. It is a multi-factorial disease and it progress through multistep progression ending in liver cirrhosis orhepatic failure. The major and well renowned etiology factors of $\mathrm{HCC}$ is hepatic viral infections like HBV, HVC, exposures to carcinogenic chemicals and heavy metals, ingestion of fungal toxins like aflatoxins and surplus accumulation of iron in the body [2]. More than $80 \%$ of global plant diversity is present in the marine atmosphere with high seaweeds and diversity of other marine macro algae species. Seaweeds are considered as the chief sources of medicinal and pharmaceutical products occurs in the marine ecosystem. Sea weeds are rich in nutritional values like vitamins, proteins and carbohydrates with less percentage of calories and traditionally they have been taken as medicine and in daily diet [3]. Macro algae from marine are the key resources of bioactive metabolites for the pharmaceutical manufacturers in drug discovery and development. Many scientific investigations identified that, the sea weeds are potential therapeutic agent for the management of variety of viral, bacterial, fungal and other chronic ailments because of their natural antioxidant property [4].

Marine green macro alga Ulva fasciata Delile belongs to the family Chlorophyceae occur bountifully in the coastal regions. It occurs plenteously in south India costal area and are rich resources of many minerals, amino acids, vitamins etc. Ulva fasciata Delile is known for their medicinal and antioxidant properties which grow on intertidal rocks, in tidepools, and on reef flats [5]. Recent investigations displayed that sea weeds are potent anticancer agents because of their anti-proliferative activity and antigenotoxic effect in human cancer cell lines and cancer inhibiting activity in experimental models. The present experiment attempts to assess the anti-tumour activity of methanolic extract of marine green macro alga Ulva fasciata Delile.

\section{Materials and Methods}

\section{Ulva fasciata extract preparation}

$U$. fasciata wash arvested from all over the substrate from intertidal region of Mandapam, Tamil Nadu, India. Fresh 
macro green algae $U$. fasciata were washed with initially with marine water and with fresh water to confiscate unwanted suspended materials, salt deposits, epiphytes and microorganism. After repeated washing, samples were stored at $-20^{\circ} \mathrm{C}$. U. fasciata samples (1600 g) were air dried, coarsely powered and extracted with solvent methanol under shaking on a rotary shaker table at $50^{\circ} \mathrm{C}$ for 1 week. Then the methanolic extract of $U$. fasciata was filtered and concerted in vacuo at $40-50{ }^{\circ} \mathrm{C}$ till the formation of dark green coloured residue (100 $\mathrm{ml})$ and was fractionated with ethyl acetate (EtOAc). After solvent evaporation, EtOAc extract formed a brown coloured viscous oily residue. The marine alga methanol extract was employed for further tests.

\section{In vitro antioxidant studies}

DPPH (2,2-Diphenyl-1-picrylhydrazyl) radical scavenging was assayed [6], Measurement of Nitric Oxide generated from sodium nitroprusside (SNP) was carried out [7], Superoxide anion scavenging activity estimation by the method [8] with minor modifications [9]. The protective role of methanolic extract of $U$. fasciata on the suppression of free radical mediated DNA-sugar damage was assayed [10]. The estimation of antioxidant by the FTC method [11,12] were followed as slightly modified [13]. Overall antioxidant activities of the methanolic extract of $U$. fasciata were estimated through Ferric thiocyanate (FTC) and Thiobarbituric acid method (TBA).TBA method was carried out [14].

\section{Anti-bacterial activity}

Anti-bacterial and anti-fungal activities of $U$. fasciata were studied in this investigation. Methanolic extract of $U$. fasciata were subjected for anti-microbial potential through disc diffusion method in contradiction of gram-positive and gramnegative bacterial culture, by the method of Gillespie (1994). The decontaminated (autoclaved at $120^{\circ} \mathrm{C}$ for $30 \mathrm{~min}$ ) medium $\left(40^{\circ} \mathrm{C}-50^{\circ} \mathrm{C}\right)$ was inoculated with the suspension of the various microorganisms and poured into Petri dishes to form 3-4 mm depth. Various $(50,100$ and $150 \mu \mathrm{g} / \mathrm{ml})$ concentration of $U$. fasciata were prepared in distilled water separately. Sterile discs (prepared frompre-sterilized (UV lamp) Whatmann filter paper) dipped in specified concentration of the extracts and standard (Ciprofloxacin, $100 \mu \mathrm{g} / \mathrm{ml}$ ). The impregnated discs are dipped in distilled water and dried was used as control. The Petri plates were saved at room temperature and allowed for 18 $\mathrm{h}$ at $37^{\circ} \mathrm{C}$ for incubation. The control and extracts zone of inhibition diameter were measured.

Gram-positive organisms: Staphylococcus epidermis (ATC 155), Staphylococcus aureus (ATCC 9144), Micrococcus luteus (ATCC 4698), Bacillus cereus (ATCC 11778), Bacillus subtilis (ATCC 11778), Streptococci mutans (ATCC 35668).

Gram-negative organisms: Escherichia coli (ATCC 25922), Klebsiella pneumonia (ATCC 11298), Pseudomonas aeruginosa (ATCC 1688).

\section{Anti-fungal activity}

Aqueous extract of $U$. fasciata was screened for antifungal activity by disc diffusion method [15]. Sabouraud dextrose agar medium as used for the study. At $45^{\circ} \mathrm{C}$, microorganism's suspension was added to sterile sabouraud dextrose agar medium. These microorganism and medium mixture was shifted to sterile petri-dishes and permissible to solidify. Different concentrations $(50,100$ and $150 \mu \mathrm{g} / \mathrm{ml})$ of the methanolic extract of $U$. fasciata sterile discs was placed on the agar plates surface and a dried disc was used as a control. The petri plates were kept at room temperature for $1 \mathrm{hr}$ and allowed for incubation at $37^{\circ} \mathrm{C}$ for 18 hours. The zone of inhibition diameter was calculated.

Fungal organisms: Aspergillus niger (ATC 9029), Aspergillus fumigates (ATC 46645), Candida albicans (ATCC 10231).

\section{Cell culture}

Screening and recognizing efficient anticancer drugs through in vitro analysing methods has been considered as foremost step in the field of cancer biology. HepG2 cell line was established from human hepatoma. The cells grew as monolayer culture in RPMI-1640 medium. HepG2 are considered an excellent model to investigate mitochondrial toxicity not only because of the high number of organelles and mitochondrial DNA present in such cells. Liver cancer cell line HepG2 was collected form NCCS (National Centre for Cell Sciences), Department of Biotechnology, Pune, India. In RPMI-1640 medium, cells were grown as monolayer complemented with 10\% (v/v) heat deactivated FBS (Fetal Bovine Serum), antibiotics (Penicillin $100 \mathrm{U} / \mathrm{ml}$, Streptomycin $10 \mu \mathrm{g} / \mathrm{ml}$ ) and $1 \mathrm{mM}$ sodium pyruvate under standard conditions $\left(37^{\circ} \mathrm{C}, \quad 5 \% \mathrm{CO}_{2}\right)$ in a measured humidified atmosphere. Every three days the medium was reformed. Cultured cells were starred, for $24 \mathrm{~h}$ trypsinized (0.05\% trypsin and $0.02 \%$ EDTA), seeded at a density of $1 \times 104$ cells per well in 96 well plate for MTT assay or at a density of $0.5 \times 106$ cells per well for LDH leakage assay and GSH assay incubated with or without 5 or $10 \mu \mathrm{l}$. fasciata extract for $24 \mathrm{~h}$. The cells were trypsinized and centrifuged at $2500 \mathrm{rpm}$ for min after the treatment of the cells.

\section{Cell viability analysis by MTT Assay}

Translation of MTT (3-(4,5-dimethylthiazol-2-yl)-2,5diphenyltetrazolium bromide) to MTT-formation by mitochondrial enzymes is the working principle of MTT assay considered as foremost methodology to access cell proliferation in invitro method. $2 \times 105$ cells were cultured with $0.5 \mathrm{ml} \mathrm{medium} /$ well in 24 well tissue culture plates at $37^{\circ} \mathrm{C}$ for $48 \mathrm{~h}$ under $5 \% \mathrm{CO}_{2}$ and $95 \%$ relative humidity. The cells were treated for $48 \mathrm{~h}$ at different concentration of drug. Before harvesting, $200 \mu \mathrm{l}$ of MTT solution $(5 \mathrm{mg} / \mathrm{ml})$ was added to each well and the plates incubated for $4 \mathrm{~h}$ at $37^{\circ} \mathrm{C}$. Unread MTT and medium were then removed by gentle aspiration. DMSO $(500 \mu \mathrm{l})$ was added to each well and the plates were gently shaken for $5 \mathrm{~min}$ at room temperature. $1 \mathrm{ml}$ 
DMSO was added to the well to extract the crystallized dye. The amount of blue dye formed was determined by measuring the absorbance at $570 \mathrm{~nm}$. The proportion survival was determined by comparing the absorbance for treated cells to that obtained for control cells. Based on the above studies, 80 and $100 \mu \mathrm{l}$ of methanolic extract of seaweed treatment for $24 \mathrm{~h}$ was selected for further experiments. The cell lines were divided into three groups. The cells were incubated at $37^{\circ} \mathrm{C}$ in a controlled humidified atmosphere of $5 \% \mathrm{CO}_{2}$ and $95 \%$ air for $48 \mathrm{~h}$ and further experiments were carried out in three groups.

\section{Lactate Dehydrogenase (LDH) leakage assay}

Leakage of LDH assay was completed by the method [16]. 100 $\mu 1$ of sample from the growth medium of experimental cultures was added to a $1 \mathrm{ml}$ cuvette containing $0.9 \mathrm{ml}$ of a reaction mixture to yield a final concentration of $1 \mathrm{mM}$ pyruvate, 0.15 mM NADH and $104 \mathrm{mM}$ disodium hydrogen phosphate buffer (pH 7.4). After thorough mixing, the absorbance of the solution was measured at $340 \mathrm{~nm}$. LDH activity was expressed as $\mu$ moles of NADH used/min/well.

\section{Estimation of glutathione (GSH)}

Reduced glutathione was estimated [17]. HepG2 ells were sonicated with homogenizing buffer and $1 \mathrm{ml}$ of 5\% TCA was added to the homogenate after the treatment. Through centrifugation process the precipitate was removed. To make a final volume of $3 \mathrm{ml}$, to an aliquot of the supernatant $2 \mathrm{ml}$ of DTNB reagent was added. The absorbance was read at $412 \mathrm{~nm}$ against a blank containing TCA instead of sample. Aliquots of the standard solution were treated similarly. The amount of glutathione was expressed as $\mu \mathrm{g} / \mathrm{mg}$ protein.

\section{Statistical Analysis}

The results were displayed as the mean \pm standard deviation (SD). Significant changes between the groups were distinguished using One-way analysis of variance (ANOVA). For statistical analysis, commercial software program (SPSS version 16) was used.

\section{Results}

Superoxide, hydroxyl, hydroperoxyl, peroxyl and alkoxyl radicals are various forms of free radicals generated during aerobic respiration in our human system. In healthy humans, commonly these naturally occurring antioxidants remove and regulator the creation of free radicals. Major contribution of antioxidants is defending the cellular damage from oxidative lipid peroxidation and impede the establishment of toxic oxidation products, help maintain the nutritional quality and increase their shelf life. Plants are rich bases of phytochemicals likely a-tocopherol and ascorbic acid and bioactive compounds helps in maintaining the quality of life [18]. U. fasciata free radicals deceiving capability was calculated using DPPH method. Figure 1 shows the free radical trapping at several concentrations from 100, 200, 300, 400 and $500 \mu \mathrm{g} / \mathrm{ml}$. Surprisingly $U$. fasciata parades more than $50 \%$ outstanding activity at the concentration of $300 \mu \mathrm{g} / \mathrm{ml}$, when nearly compared with the standard Vitamin C. Figure 2 represents the trapping of the Nitric oxide radicals by various concentrations $(100,200,300,400$ and $500 \mu \mathrm{g} / \mathrm{ml})$ of the methanolic extract of $U$. fasciata. The extract showed strong free radical hindering activity when equated with the standard Vitamin C. From these results, it is inferred that the extract might be a potent peroxide inhibitor.

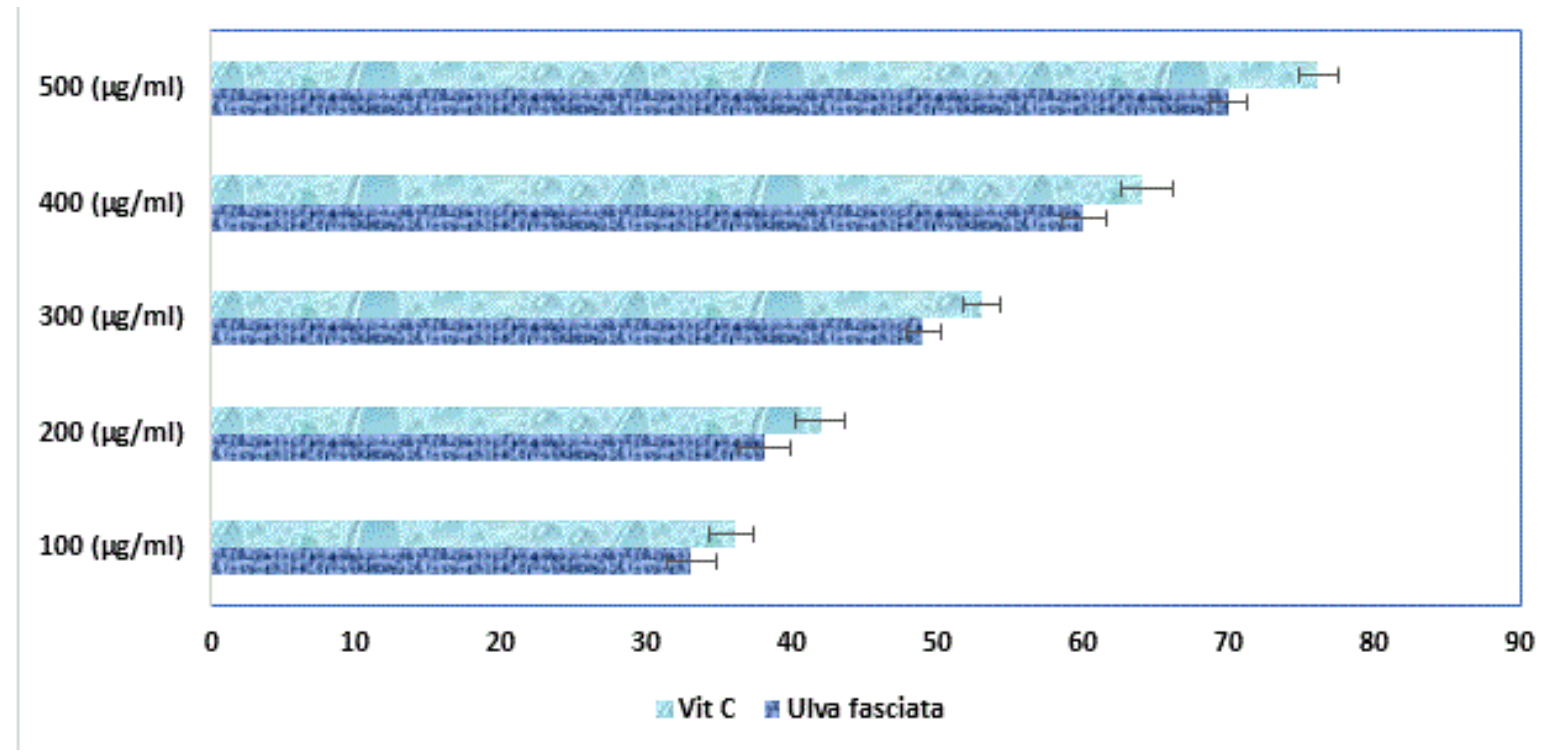

Figure 1. Free radical trapping of methanol extract of Ulva fasciata by DPPH method, Values are mean $\pm S D$ of triplicate determinations 


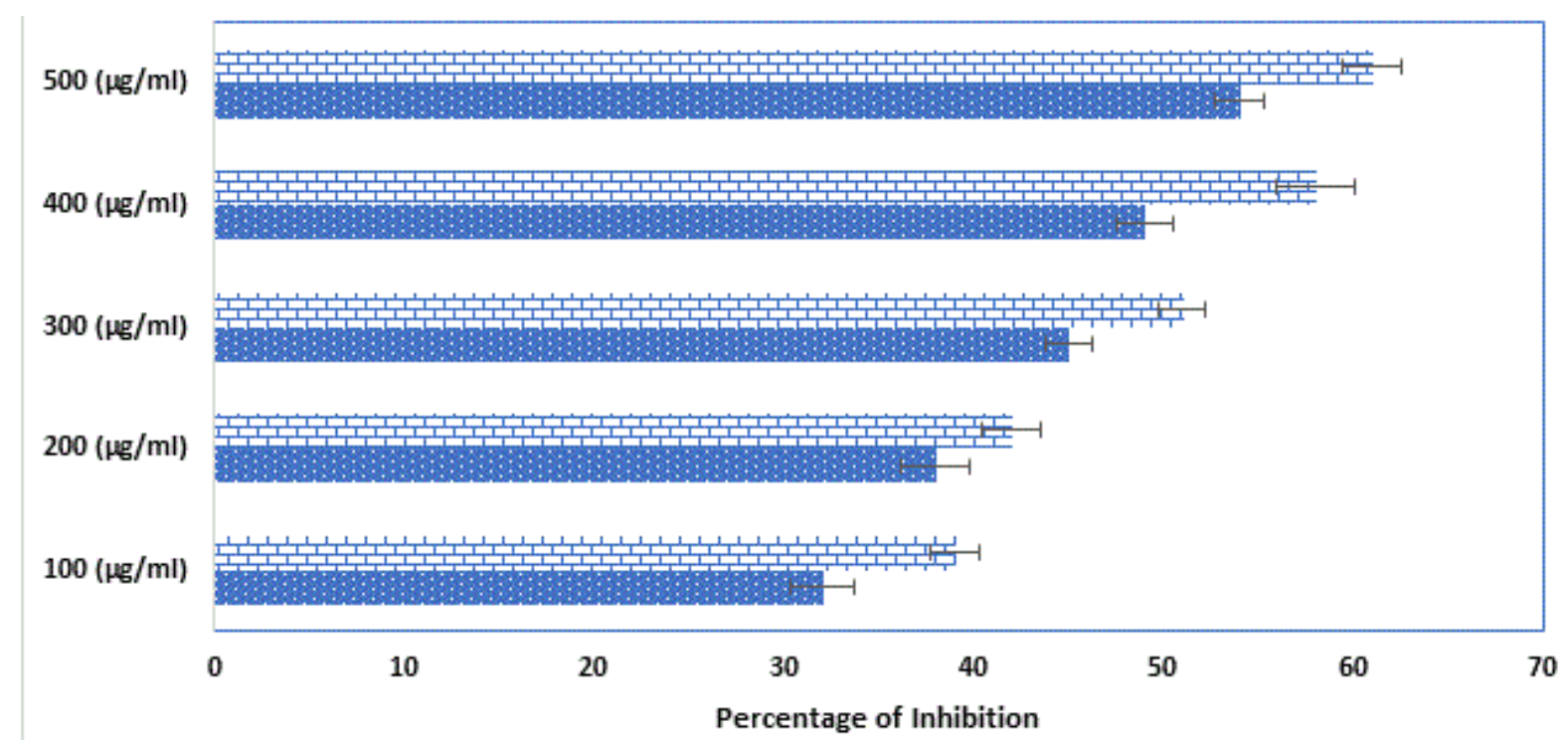

Figure 2. Nitric oxide radical trapping activity of methanol extract of Ulva fasciata. Values are mean \pm SD of triplicate determinations

Super oxide free radicals are involved in many pathological conditions which produce deleterious effects in tissues of biological origin. In the present investigation, the dose dependent inhibition of super oxide radicals by the aqueous extract of $U$. fasciata was performed and the results obtained were presented in Figure 3. The results showed the aqueous extract of $U$. fasciata significantly inhibited the super oxide radicals at various concentrations of 100, 200, 300, 400 and $500 \mu \mathrm{g} / \mathrm{ml}$. A notable inhibition of super oxide was observed in the concentration of $300 \mu \mathrm{g} / \mathrm{ml}$ itself with more than $50 \%$ of inhibition and this was comparatively well with the standard vitamin C. Generally, when the free radicals are involved in the base pairs of DNA and which ultimately leads in the aetiology of various diseases in biological system. Thus, protection of the reaction on sugar moieties of the DNA base pairs from ROS may be useful in the disease condition. The protective role of DNA sugar damage was presented in Figure 4. From this figure, it was observed that the extract of the $U$. fasciata remarkably prohibited the free radical facilitated DNA sugar damage at dose dependent manner.

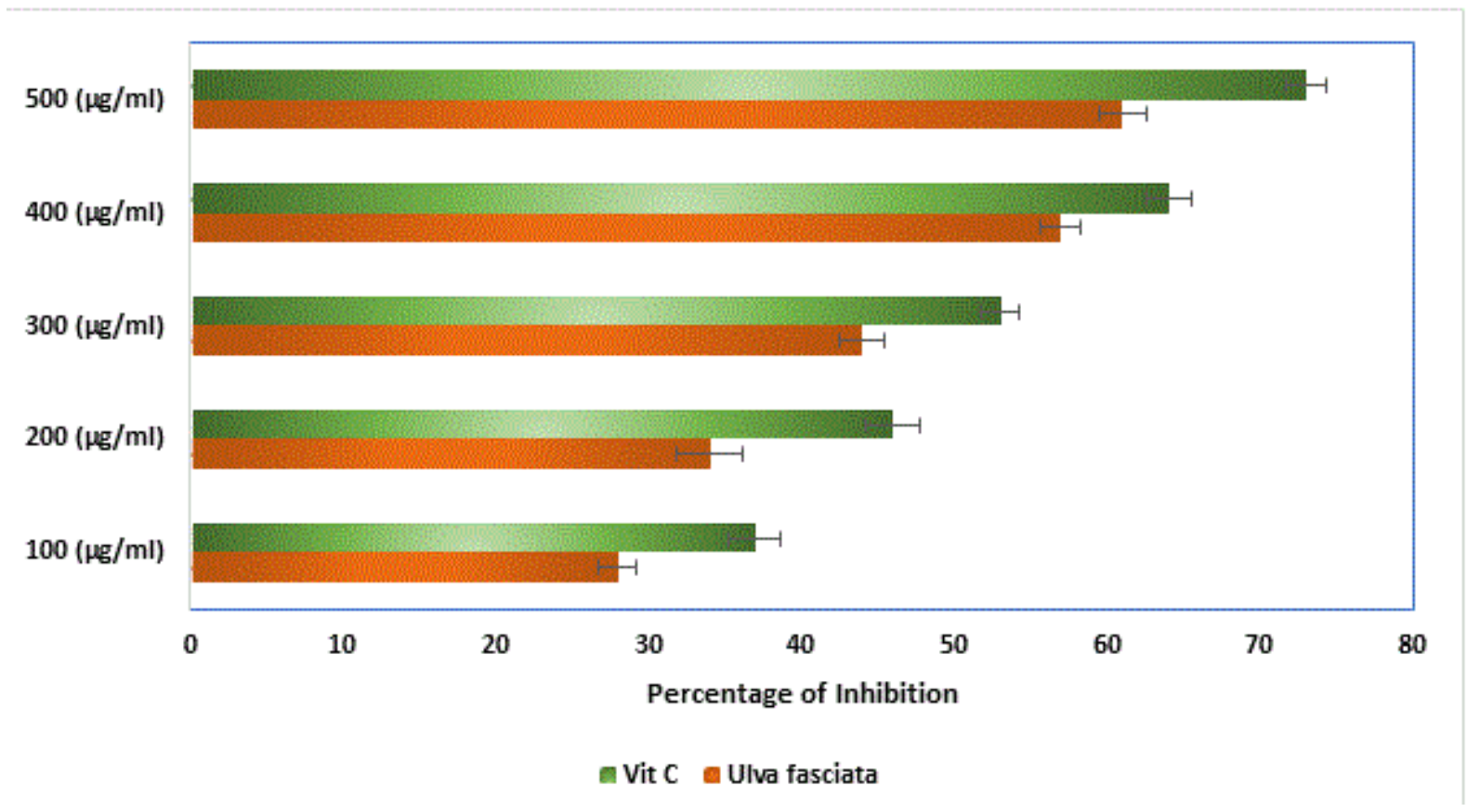

Figure 3. Superoxide anion radical trapping activity of methanol extract of Ulva fasciata. 


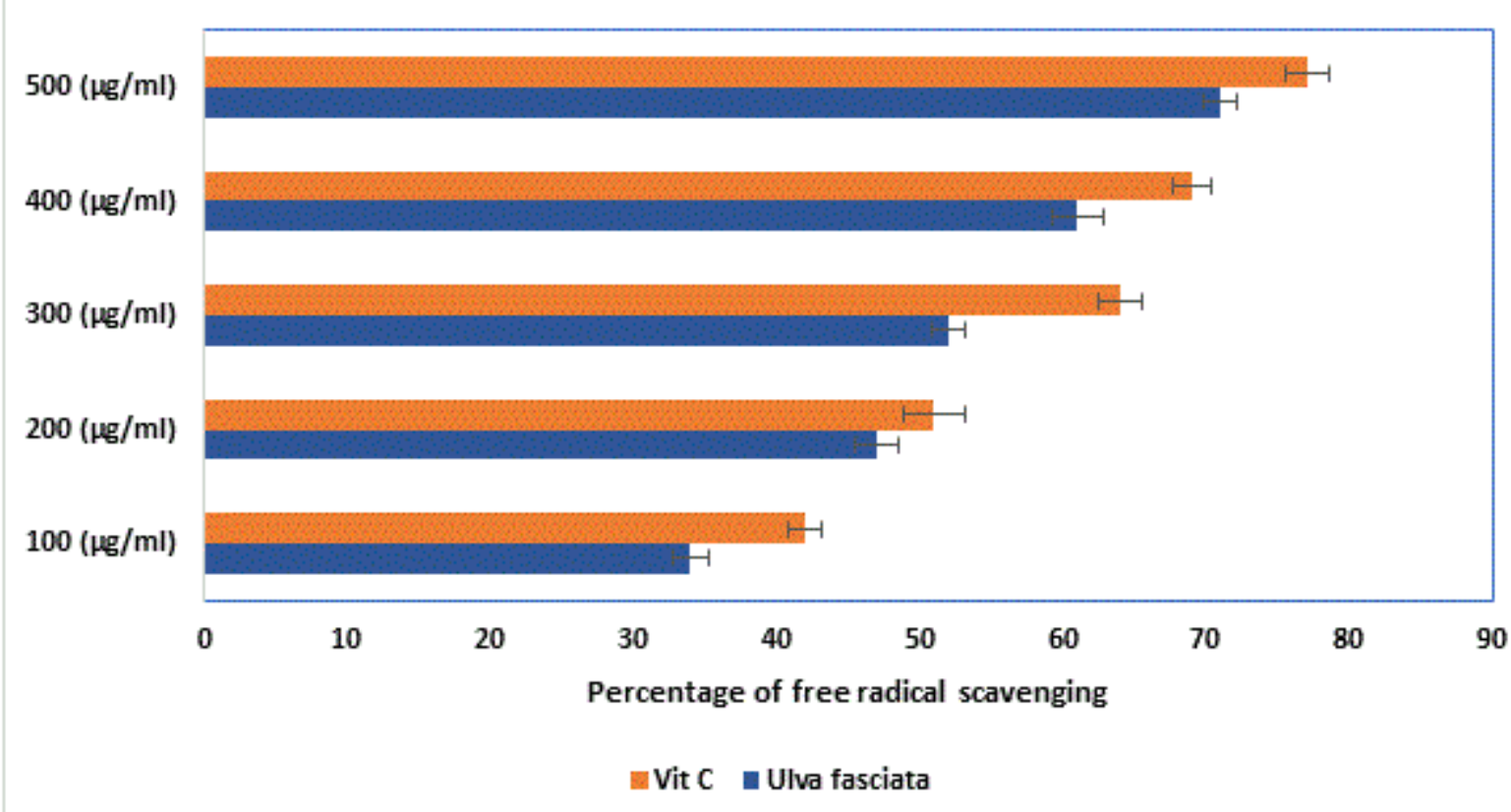

Figure 4. Protective effect of methanol extract of Ulva fasciata on DNA sugar damage.

Ferric thiocyanate (FTC) and Thiobarbituric acid (TBA) are the two noteworthy methods to analyse the total antioxidant potential of the plant extract. FTC is used to quantify the fabrication of peroxide compound at the preliminary phase of oxidation where as in the TBA method the subordinate product of oxidation such as aldehyde and ketone were measured.
Figures 5 and 6 illustrate the antioxidant potential of methanolic extract of $U$. fasciata by FTC and TBA technique. In this study, the extract of $U$. fasciata evidently repressed the oxidation of linoleic acid for the period of 6 days with nearly $50 \%$ when related with the standard Vitamin E.

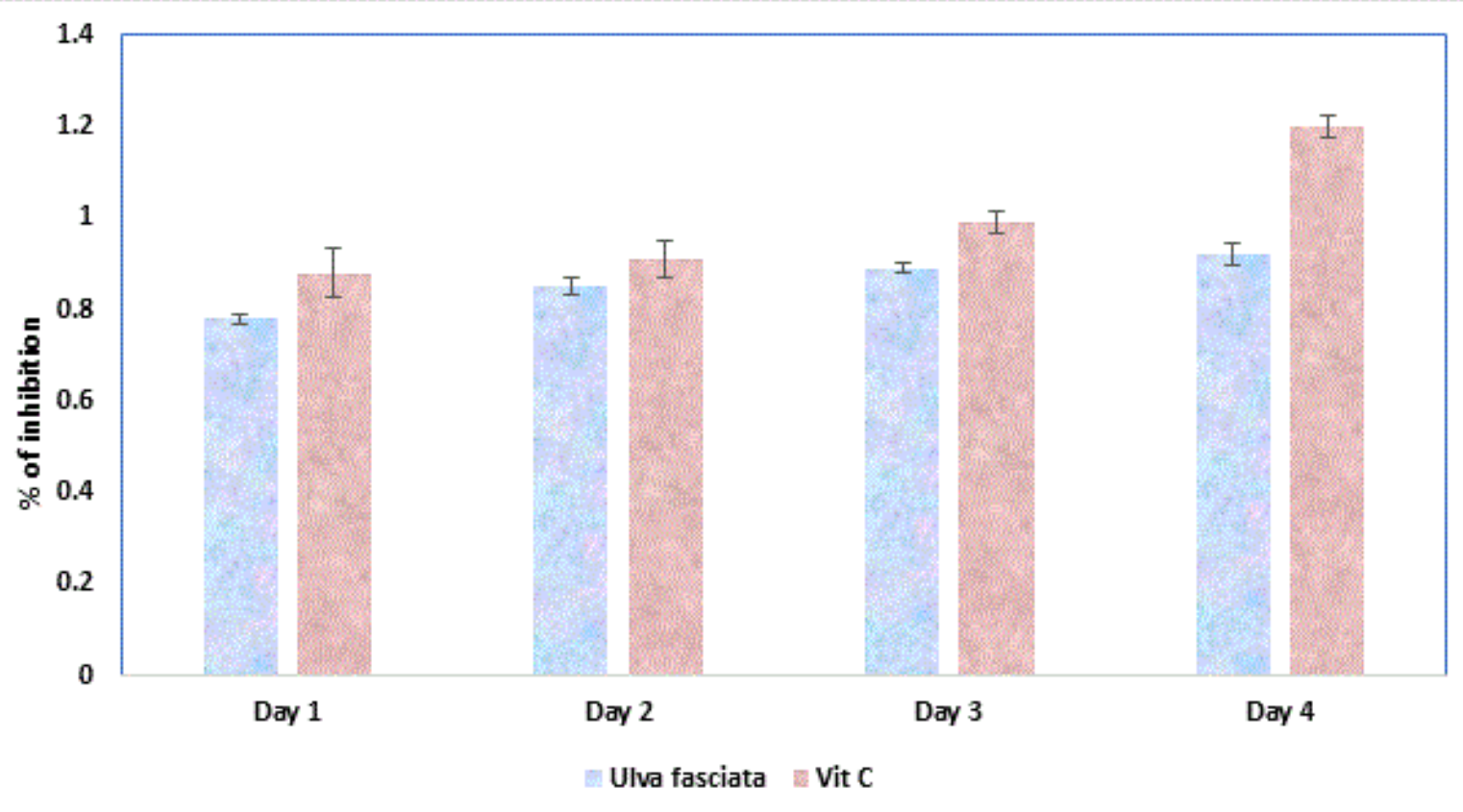

Figure 5. Antioxidant activity of methanol extract of Ulva fasciata by FTC method. 


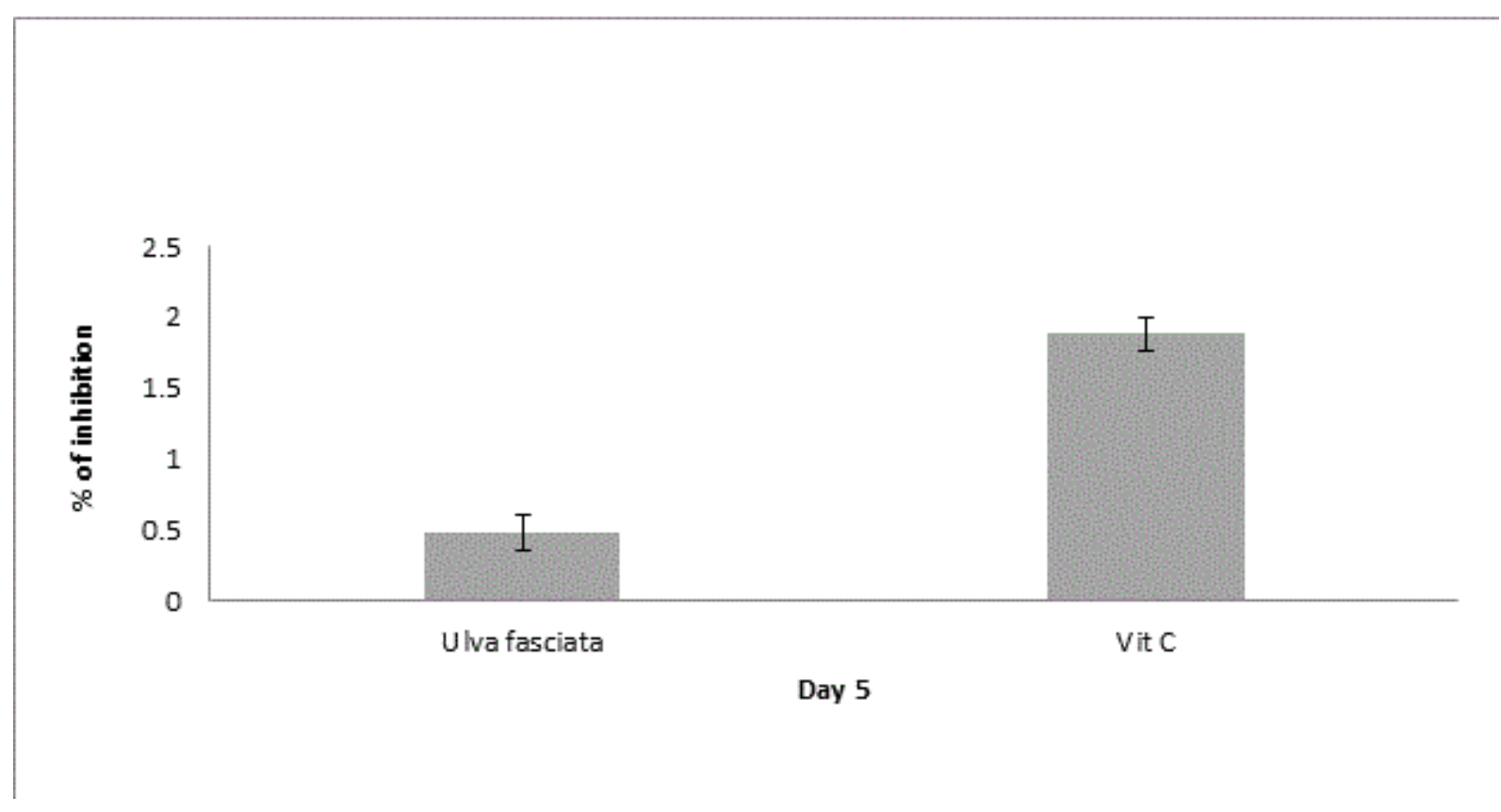

Figure 6. Antioxidant activity of methanol extract of Ulva fasciata by TBA method.

Figures 7-9 shows the antimicrobial efficacy of the methanol extract of $U$. fasciata was analysed. In the present examination, the extract of $U$. fasciata in the dose levels of 50,100 and 150 $\mu \mathrm{g}$ controlled the growth of gram positive, gram negative bacterial and fungal organisms was displayed in the Figures 7, 8 and 9 respectively. Ciprofloxacin $5 \mu \mathrm{g} / \mathrm{disc}$ was used as the standard for gram positive and gram negative bacteria. Ketoconazole $50 \mu \mathrm{g} /$ disc was used as a standard for fungus. The zone of inhibition gives the evidence about the antimicrobial effect of extract. It was assessed that the methanolic extract of $U$. fasciata has the capacity to inhibit the growth of the bacterial and fungal organisms by disc diffusion method. The present scrutiny analysed $U$. fasciata cytotoxic efficacy and anti-tumour activity on HepG2 cell line. The drug cytotoxic probable, leakage of lactate dehydrogenase activity and estimation of GSH of $U$. fasciata were investigated. Experimental study regarding bioactive compounds and plant derived natural substances cytotoxic efficiency against cancerous cells is considered as the preliminary screening in the therapeutic analysis [19].

With the help of reliable method MTT assay to perceive proliferation of cells, the cytotoxic and anti-proliferative potential of $U$. fasciata on human hepatoma cells was studied. The treatment of methanolic extract of $U$. fasciata at different dose level $(20,40,60,80$ and $100 \mu \mathrm{l})$ for 24 and 48 hours lessened cell proliferation was displayed in Figure 10. Figure 11 illustrates the lactate dehydrogenase (LDH) leakage activity of $U$. fasciata on HepG2 cells. The figure demonstrates that, $\mathrm{LDH}$ activity was recognized to be suggestively higher at 80 and $100 \mu \mathrm{l}$. fasciata treatment for $24 \mathrm{~h}$ of exposure in the cultured medium when compared to the control. The antitumour drugs toxicity principally depends on the reduced glutathione or intracellular level. Glutathione has been considered as a magnificent defender in safeguarding the cells and their components against oxidative anxiety. Inflection of glutathione storages and destruction of glutathione synthesis in cancer conditions to diminish anti-cancer drugs resistance may comprise an innovative anticancer tactic [20].
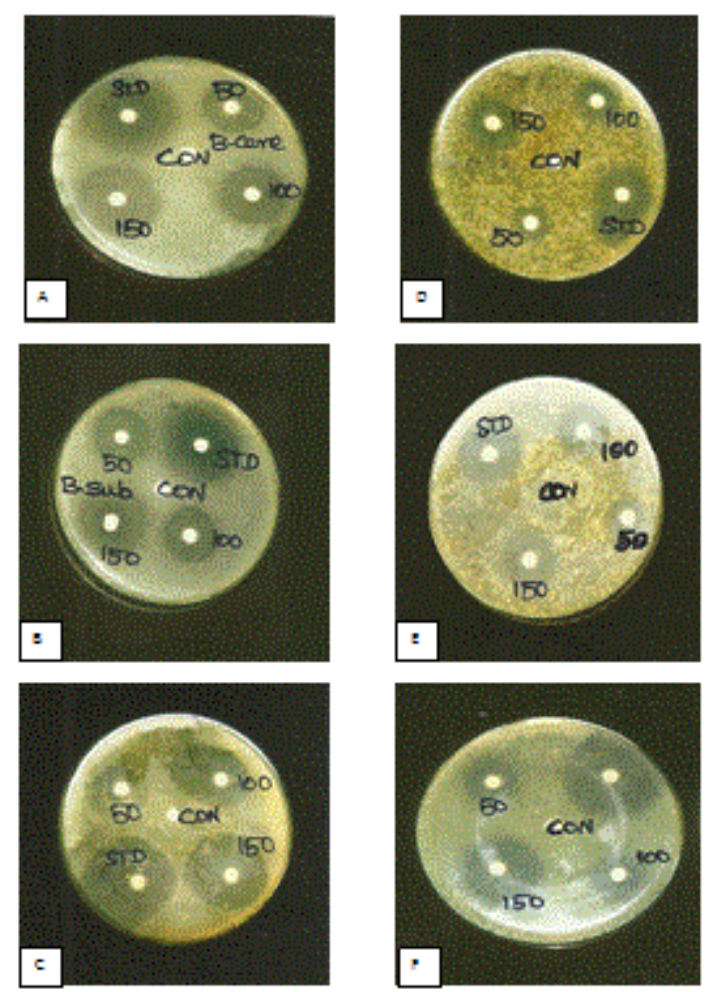

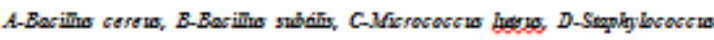

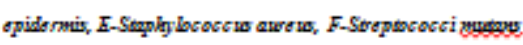

Figure 7. Antibacterial activity of $U$. fasciata against Gram-Positive organisms. 
Figure 12 demonstrates GSH content in control and U. fasciata treated HepG2 cells. Noteworthy diminution of GSH was sensed in methanolic extract of $U$. fasciata treated HepG2 cells at the concentration of 80 and $100 \mu l$ when equated to the control.

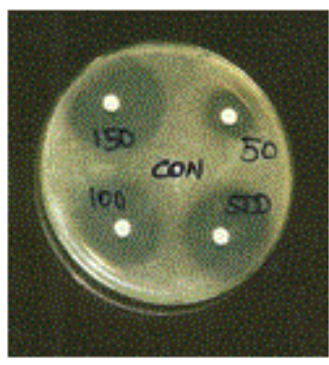

(A) Escherichia coli

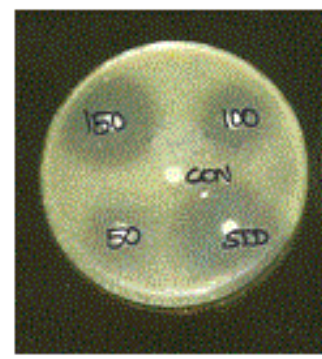

(B) Elebsiella pnewmonia

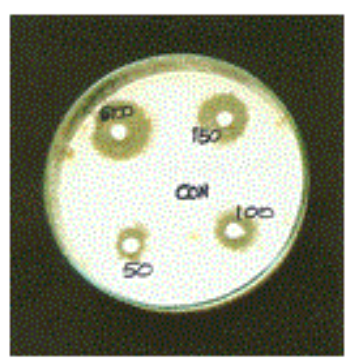

(A) Aspergillus viger

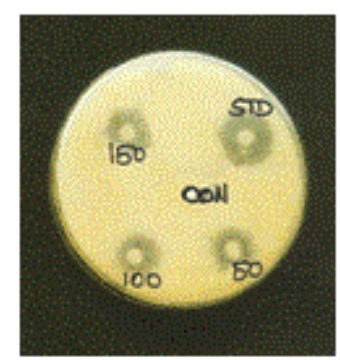

(B) Aspergillus flunigates

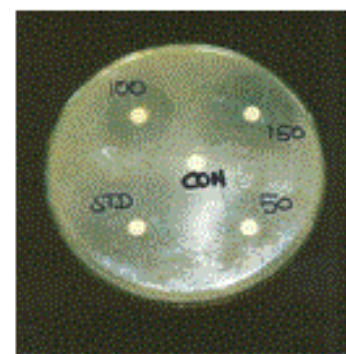

(C) Candida albians

Figure 9. Antifungal activity of $U$. fasciata

Figure 8. Antibacterial activity of $U$. fasciata against Gram-Negative organisms.

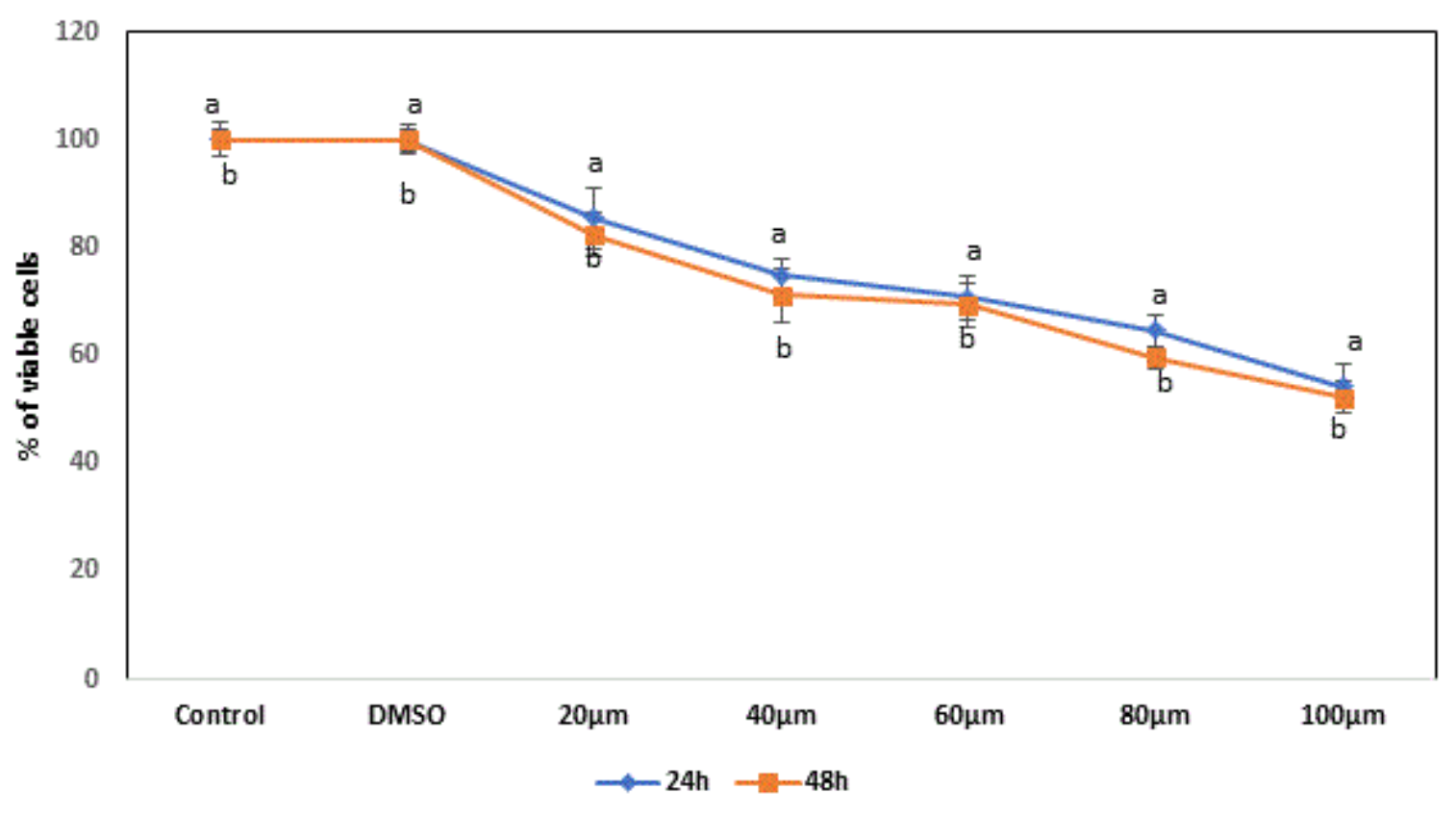

Figure 10. Cytotoxic effect of Ulva fasciata on HepG2 cells - MTT Assay. 


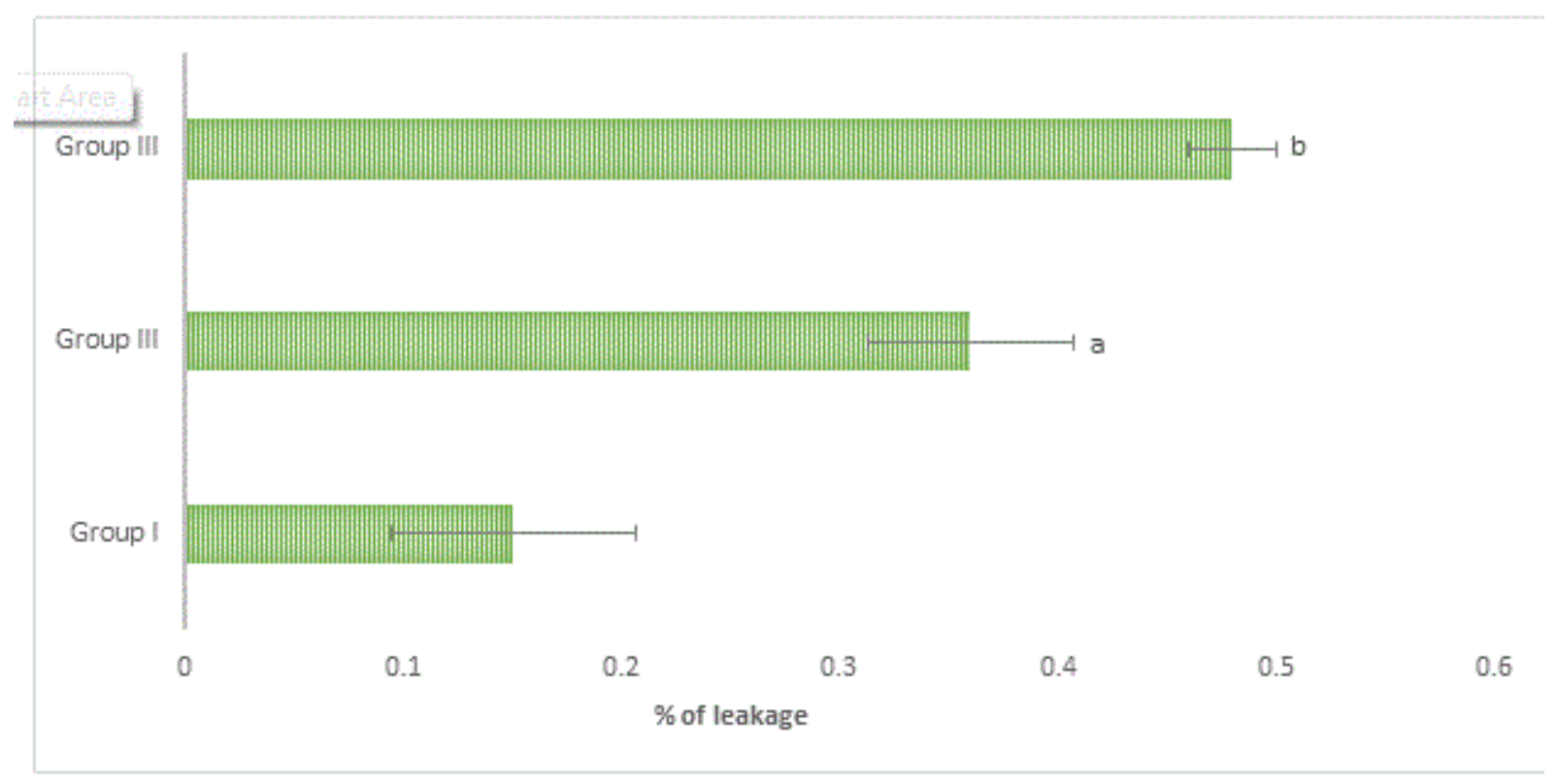

Figure 11. Viability and LDH leakage in control and Ulva fasciata treated HepG2 cells after 24 h of exposure.

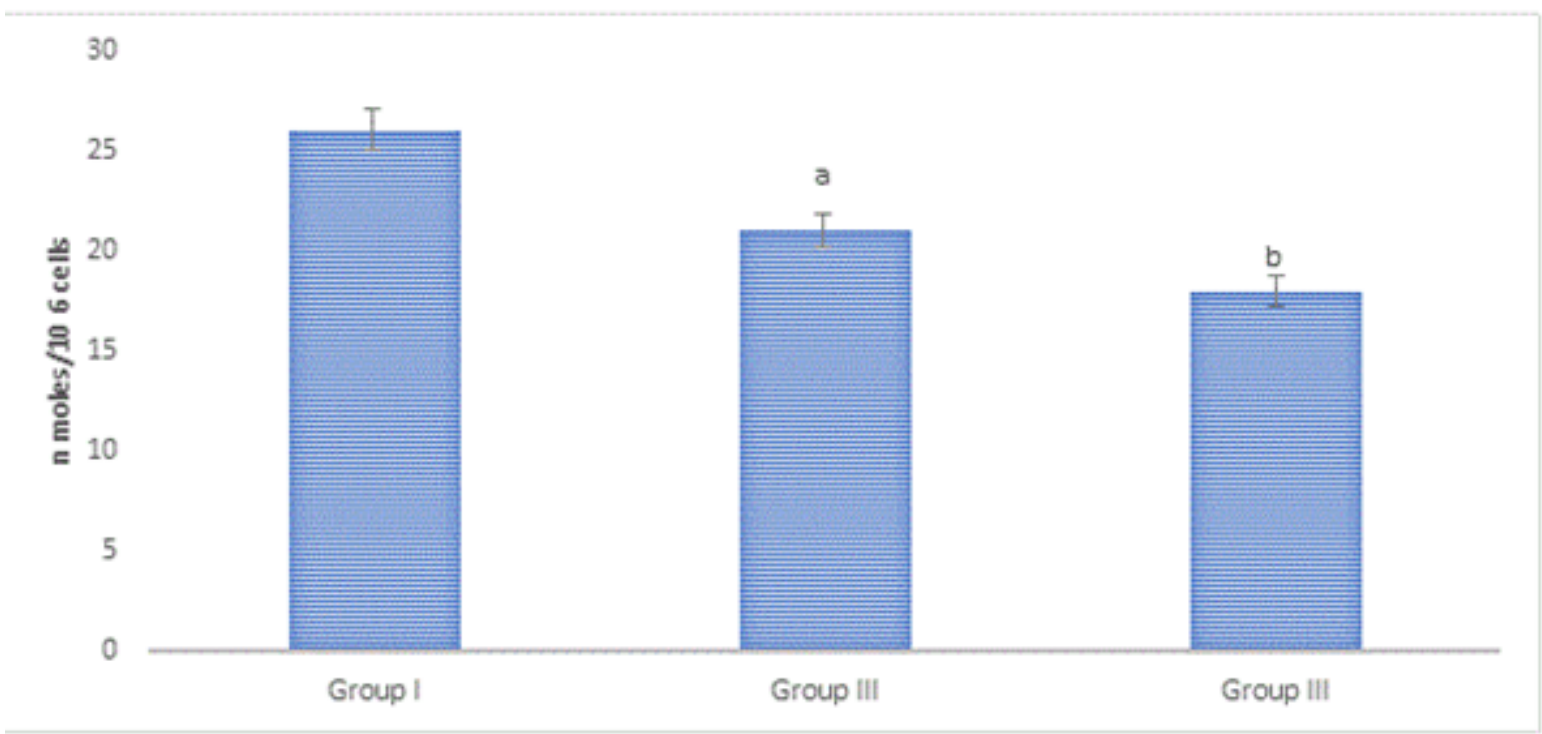

Figure 12. Levels of GSH in control and Ulva fasciata treated HepG2 cells.

\section{Discussion}

Antioxidants are measured as effective reducing representatives which guard's macromolecules namely DNA, proteins and lipids from reactive oxygen species (ROS). Superoxide $(\mathrm{O})$, Hydrogen peroxide (HO), Nitric oxide (NO) and hydroxyl $(\mathrm{OH})$ are potent ROS exert oxidative stress rendering each cell to face about 10,000 oxidative hits per second [21]. Antioxidants intended to thwart the acknowledged deleterious properties of free radicals in the human body and to avert the deterioration of fats and other constituents of foodstuffs. Currently there is an immense rise in using approaches for assessing the efficacy of antioxidant of such substances. DPPH is one of the outstanding methods to use for evaluating free radical scavenging activity of a plant. This activity is measured as the relative decrease in absorbance of $\mathrm{DPPH}$ as it reacts with the antioxidant [22]. In the present experiment, the methanolic extract of $U$. fasciata showed concentration dependant augmentation in the trapping of free radicals. This might due to the various active phytochemical constituents present in the extract of $U$. fasciata.

Neural signal transmission, immune response, control vasodilation and control of blood pressure are physiological processes necessitate nitric oxide as an indispensable bio regulatory [23]. The reaction between $\mathrm{O}_{2-}$, and $\mathrm{NO}$-results in excess production of toxic products such as NO- and $\mathrm{ONOOH}$ has been coupled with various factors and pathology of chronic disorders. The plants and their bioactive products have the efficient to frustrate the effect of $\mathrm{NO}$ formation. $U$. fasciata 
condensed the generation of $\mathrm{NO}$ in vitro in a concentration dependent manner. Mitochondrial electron transport systems generate superoxide anion as a primary free radical. In the living system, superoxide anion plays a dynamic part in the foundation of other ROS such as hydrogen peroxide, hydroxyl radical, or singlet oxygen which are toxic to macromolecules [24]. In the present examination, it is inferred that methanolic extract of $U$. fasciata exhibits admirable superoxide quenching activity. This may be due to the phenolic content present in the extract of $U$. fasciata.

Oxidative damage to DNA represents an early stage of cancer and provides a valuable marker of overall oxidative stress. In the present analysis, the methanol extract of $U$. fasciata inhibits DNA damage by quenching free radicals. This may be due to the existence of components of the extract containing isoflavonoids, anthocyanins, phenolic compounds and some proteins that have antioxidant activities [25]. The methanol extract of $U$. fasciata total antioxidant potential was estimated by the FTC method and related with the TBA method. The FTC method calculates the capability of antioxidants to rummage peroxyl radicals, which counter with polyunsaturated fatty acids, through hydrogen donation. The TBA method quantify free radicals existing after peroxide oxidation. Portentous antioxidant consequence was exhibited by methanol extract of $U$. fasciata in this experiment which signifies that, the active phytochemical constituents occur in the plant extract play a significant role in antioxidant efficacy. In the present investigation, the dose levels in the range of 50,100 and $150 \mathrm{~g}$ of $U$. fasciata extract inhibited the growth of gram positive bacteria such as Bacillus cereus, Bacillus subtilis, Micrococcus luteus, Staphylococcus epidermis, Staphylococcus aureus and Streptococci mutans; gram negative bacteriasuch as Escherichia coli, Klebsiella pneumonia and Pseudomonas aeruginosa. The extract also inhibited the fungal organisms such as Aspergillus niger, Aspergillus fumigates and Candida albicans. Therefore, U. fasciata can be considered as an antimicrobial agent.

HCC is one of the fatal chronic diseases with deprived prognosis with high epidemiology rate throughout the world. Currently hepatocellular carcinoma is treated limited with radiation therapy, surgical resection and liver transplantation with number of side effects and they are treated only in the preliminary stage of the tumour [26]. Even though other liver cancer management therapies like transcatheter arterial chemoembolization, percutaneous intratumorally ethanol injection and radiofrequency ablation are effective when the patients are with tiny tumour diameter and systemic chemotherapy are with less recovery. A wide range of bioactive nutrients have been found useful in the physiological battle against cancer [27].

Cytotoxic assessment in in vitro cell line models is measured as one of the noteworthy and indispensable screening method for categorizing effective anti-cancer bioactive compounds and other chemicals. Cell viability and proliferation measurement is consistent to enumerate cell viability is the basis for numerous in vitro assays of a cell population's response to external factors. The results of the present investigation clearly demonstrated that, methanolic extract of $U$. fasciata different concentration exposure $(20,40,60,80$ and $100 \mu l)$ for the time of $24 \mathrm{~h}$ arrest the HepG2 cell proliferation in a time and dose dependent manner. $U$. fasciata methanolic extract at the concentrations of 80 and $100 \mu \mathrm{l}$ prevents more than $50 \%$ cell populace when compared to control after $24 \mathrm{hrs}$ of treatment. In the present study, U. fasciata methanolic extract powerfully demonstrated its anti-proliferation property and cytotoxic nature on human hepatoma cells HepG2. Further $U$. fasciata reduced the proliferation of HepG2 cells through their apoptotic activity.

Lactate dehydrogenase is present in almost all the cells of human body and it is expressed during pathological conditions, therefore $\mathrm{LDH}$ is considered as a reliable marker enzyme to measure the cytotoxicity. During chronic toxic substance exposure take the cells to be damaged and fragmented entirely. The lactate dehydrogenase leakage was amplified in $U$. fasciata methanolic extract treated HepG2 cells when compared to that of control HepG2 cells. The results of present investigation put forward that, U. fasciata anti-cancer potential and cytotoxic nature of the extract the lactate dehydrogenase leakage in HepG2 cells was heightened and authorize its antitumour action. Glutathione (GSH) is coming under the antioxidant family which protects the body under variety of toxins like ROS and from stress conditions. GSH have me known as a protective candidate against endogenously triggered oxidative stress and protects the cell damage. It has been reported that, there is a strong correlation between the decline of cellular system intercellular GSH and the onset of apoptosis. Mostly the programmed cell death triggering compounds are oxidants of cellular oxidative metabolites. Thus, the apoptotic potential of the drug is measured by the quantity of GSH in the HepG2 cells. The cellular toxicity of the drug is estimated by the rate of proportional of reduced glutathione to oxidized glutathione within the cells. In the present analysis, U. fasciata methanolic extract treated HepG2 cells showed a depletion in the content of GSH which reflects the cytotoxic property of $U$. fasciata. The drug molecule, uphold the pro and anti-apoptotic equilibrium and induced oxidative stress through cellular signalling process in the human hepatoma cells. This might be due to presence of bioactive principles like phenolic compounds and flavonoids in the seaweed extract and pro-oxidant actions. Consequently, the cytotoxic achievement of this drug may be accredited to its pro-oxidant action on the tumour cells.

\section{Conclusion}

The in vitro antioxidant effect, anti-microbial potential and anti-tumour efficacy of $U$. fasciata in hepatoma cell line (HepG2) was credible to the plant extract was defined in the present investigation. Inhibition of HepG2 cells is likely to be selective apoptotic nature of the significant biologically active $U$. fasciata. Besides U. fasciata is very much functioning in averting multi-stage hepatocarcinogenesis possibly through antioxidant and anti-genotoxic effect of the plant methanolic 
extract. Form this investigation, it was concluded that $U$. fasciata methanolic extract is an outstanding antioxidant, antimicrobial and anti-cancer contender.

\section{Contributions}

KL designed the research methodology, recruited and analysed data, wrote the manuscript; SS Language Editing; SG Computational statistics related to the manuscript.

\section{Acknowledgement}

The authors immensely thankful to Alagappa University for providing the financial assistance from AURF Start-Up Grant and laboratory facilities is gratefully acknowledged. The article has been written with the financial support of RUSA - phase 2.0 grant sanctioned vide Letter No.F.24-51/2014-U policy (TNMulti - Gen), Dept of Edn. Govt of India Dt, 09.10.2018.

\section{References}

1. Costentin C. Hepatocellular carcinoma surveillance. Presse Med 2017; 46: 381-385.

2. Clark T, Maximin S, Meier J, Pokharel S, Bhargava P. Hepatocellular carcinoma: review of epidemiology, screening, imaging diagnosis, response assessment, and treatment. Curr Probl Diagn Radiol 2015; 44: 479-486.

3. Pina-Perez MC, Rivas A, Martínez A, Rodrigo D. Antimicrobial potential of macro and microalgae against pathogenic and spoilage microorganisms in food. Food Chem 2017; 235: 34-44.

4. Mashjoor S, Yousefzadi M, Esmaeili MA, Rafiee R. Cytotoxicity and antimicrobial activity of marine macro algae (Dictyotaceae and Ulvaceae) from the Persian Gulf. Cytotechnol 2016; 68: 1717-1726.

5. Ramadas AA, Jose R, Arathy SL, Kurup S, Chandy ML, Kumar SP. Systemic absorption of $0.1 \%$ triamcinolone acetonide as topical application in management of oral lichen planus. Indian J Dent Res 2016; 27 : 230-235.

6. Hatano $\mathrm{T}$, Edamatsu R, Hiramatsu M, Mori A, Fujita Y. Effect of interaction of tannins with co-existing substances VI. Effect of tannins and related polyphenols on superoxide anion radical and on DPPH radical. Chem Pharmaceutical Bull 1989; 37: 2016-2021.

7. Marcocci L, Maguire JJ, Packer L. Nitecapone: a nitric oxide radical scavenger. Biochem Mol Biol Int 1994; 34: 531-541.

8. Liu F, Oovi VFC, Chang ST. Free radical scavenging activity of mushroom polysaccharide extracts. Life Sci 1997; 60:763-777.

9. Gulcin I, Ugvuz MT, Oktay M, Beydemir S, Kiifrevioglu OI. Antioxidant and antimicrobial activities of Tencrium polium L. J Food Technol 2003; 1: 9-17.

10. Halliwell B, Gutteridge JMC. Formation of a thiobarbituric acid reactive substances from deoxyribose in the presence of iron salts. The role of superoxide and hydroxyl radicals. FEBS Lett 1981; 128: 347-352.
11. Mitsuda H, Yasumoto K, Iwani K. Antioxidant action of indole compounds during the autoxidation of linoleic acid. Eiyo to Shoduryo 1967; 19: 210.

12. Osawa T,Namiki M. A novel type of antioxidant isolated from leaf wax of Eucalyptus leaves. Agri Biol Chem 1981; 45: 735-740.

13. Kikuzaki H, Nakatani N. Antioxidant effects of some ginger constituents. J Food Sci 1993; 58: 1407-1410.

14. Ottolenghi A. Interaction of ascorbic acid and mitochondaria lipids. Arch Biochem Biophys 1959; 79: 355-359.

15. Gillesbie SH. Medical Microbiology-Illustrated. Butterworth Heinemann Ltd, London, 1994; 234-237.

16. Grivell AR, Berry. The effect of phosphate and substrate free incubation conditions on glycolysis in Ehrich ascites tumour cells. Biochim Biophys Acta 1996; 1291: 83-88.

17. Moron MS, Depierre JW, Mannervik B. Levels of glutathione reductase and glutathione-S-transferase activities in rat lung and liver. Biochem Biophys Acta 1979; 582: 67-78.

18. Teow CC, Truong VD, McFeeters RF, Thompson RL, Pecota KV, Yencho GC. Antioxidant activities, phenolic and b-carotene contents of sweet potato genotypes with varying flesh colours. Food Chem 2007; 103: 829-838.

19. Pomp J, Wike JL, Ouwerkerk IJ, Hoogstraten C, Davelaar J, Schrier PI, Leer JW, Thames HD, Brock WA. Cell density dependent plating efficiency affects outcome and interpretation of colony forming assays. Radiother Oncol 1996; 40: 121-125.

20. Yang D, Wang D, Shimer A, Shen FH, Li X, Yang X. Glutathione protects human nucleus pulposus cells from cell apoptosis and inhibition of matrix synthesis. Connect Tissue Res 2014; 55: 132-139.

21. Banerjee S, Chanda A, Ghoshal A, Debnath R, Chakraborty S, Saha R, Das A. Nitric Oxide Scavenging Activity Study of Ethanolic Extracts of from Two Different Areas of Kolkata Ixoracoccinea. Asian J Exp Biol Sci 2011; 2: 595-599.

22. Rumbaoa RGO, Cornago DF, Geronimo IM. Phenolic content and antioxidant capacity of Philippine sweet potato (Ipomoea batatas) varieties. Food Chem 2009; 113: 1133-1138.

23. Jagetia GC, Rao SK, Baliga MS, Babu KS. The evaluation of nitric oxide scavenging activity of certain herbal formulationsin vitro: a preliminary study. Phytother Res 2004; 18: 561-565.

24. Truong VD1, McFeeters RF, Thompson RT, Dean LL, Shofran B. Phenolic acid content and composition in leaves and roots of common commercial sweetpotato (Ipomea batatas L.) cultivars in the United States. J Food Sci 2007; 72: 343-349.

25. Kuda T, Tsunekawa M, Goto H, Araki Y. Antioxidant properties of four edible algae harvested in the Noto Peninsula, Japan. J Food Compost Anal 2005; 18: 625-633. 
26. Chonprasertsuk S, Vilaichone RK. Epidemiology and treatment of hepatocellular carcinoma in Thailand. Jpn J Clin Oncol 2017; 47: 294-297.

27. Khan MI, Rath S, Adhami VM, Mukhtar H. Targeting epigenome with dietary nutrients in cancer: Current advances and future challenges. Pharmacol Res 2018; 129: 375-387.

\section{*Correspondence to}

V. K. Langeswaran

Cancer Genetics and Molecular Biology Laboratory Department of Bioinformatics

Alagappa University, Karaikudi

India 